\title{
Using Generalized Procrustes Analysis for Evaluation of Sensory Characteristic Data of Lamb Meat
}

\author{
Gazel Ser',a,* \\ ${ }^{I}$ Department of Animal Science, Faculty of Agriculture, Van Yüzüncü Yll University, 65080 Campus/Van, Turkey \\ ${ }^{*}$ Corresponding author

\begin{tabular}{l|l}
\hline A R T I C L E I N F O & A B S T R A C T \\
Research Article & $\begin{array}{l}\text { Generalized Procrustes Analysis (GPA) is a multivariate statistic method that is used at the } \\
\text { evaluation of sensory analyses in the food industry. GPA provides benefit in terms of decreasing the } \\
\text { difference between the panellists and bringing the data obtained from different panellists together. } \\
\text { In this study, the aim was to determine the effect of a pre-slaughter fasting period on sensory } \\
\text { characteristics of lambs fed with different rations using GPA. Semi-trained panellists formed from } \\
\text { twenty-six persons were requested for evaluation of the meat samples such as tenderness, juiciness, } \\
\text { flavour and overall liking rated on a scale of 1(extremely dislike) to } 9 \text { (extremely good). The first } \\
\text { two factors obtained by GPA explained } 66.74 \% \text { of total variability. As a result of the analysis, it was } \\
\text { determined that } 12 \text { h and } 24 \text { h fasting of lambs fed barley supplemented with alfalfa hay were less } \\
\text { preferable when compared to lambs fed alfalfa hay only. In addition, lambs in both groups with } 48 \\
\text { heceived : 05/09/2018 } \\
\text { fasting were preferred less by the panellists. In conclusion, GPA analysis provides useful data } \\
\text { concerning the sensitivity of each panellist in a sensory panel test. }\end{array}$ \\
$\begin{array}{l}\text { Keywords: } \\
\text { Sensory analysis } \\
\text { Procrustes analysis } \\
\text { Meat flavour }\end{array}$
\end{tabular} \\ Meat flavour
}

Panellist behaviour

Scale

\section{Introduction}

Many factors such as feeding patterns (socio-cultural effects, lifestyle, etc.), market conditions (price, brand, etc.) and sensory characteristics affect the purchasing patterns of consumers (Font-i-Furnols and Guerrero, 2014). The main sensory characteristics of meat may be specified as appearance (colour, fat content, etc.), texture (tenderness and juiciness) and flavour. Studies have shown that genotype, age, sex, feeding and many procedures before (transportation, fasting period, etc.) and after (storage conditions, ageing period and cooking type, etc.) slaughter have important effects on sensory characteristics of meat (Ferguson and Warner, 2008; Guerrero et al., 2013; Honikel, 2004). As the relevant factors can significantly affect consumer preferences, new information is required to improve these factors in favour of consumer demands.

Sensory analysis is an analytic methodology in which human senses are used to define and measure characteristics of meat (Sanudo et al., 2007). Although sensory analysis is a subjective test, human assessments are important as they allow for a direct measure of consumer perception. Therefore, sensory panel tests are used as a reference method in many studies. But in some cases, the evaluation of panel test results is difficult because of wide variations and differences between panellist assessments (Tomic, 2013).

The sensory panel test is the most effective and appropriate tool used in the determination of the differences between samples subjected to various treatments when evaluated by educated panellists (Rodrigues and Teixera, 2009). The most important problem with sensory analysis is the wide variability in assessments of the same food sample by different panellists. Especially, the most important source of variability is the lack of consensus in describing a sample between panellists (Wu et al., 2003). The Generalized Procrustes Analysis (GPA) is a multi-variate statistical method that is used for the evaluation of sensory analysis in the food industry. GPA is beneficial in terms of decreasing the differences between the panellists and summarizing the data obtained from different panellists (Keskin et al., 2012; Rodrigues and Teixera, 2014).

In recent years, studies are available in which sensory 
analysis results have been evaluated with the GPA method (Alcalde et al., 2014; Keskin et al., 2012; Rodriquez and Teixeira, 2013). To the best of our knowledge, there is no study concerning the effect of pre-slaughter stress related to feeding system on sensory characteristics that uses the GPA method.

The aim of this study was to determine the effect of preslaughter diet/management system and fasting period on sensory characteristics of lambs with Generalized Procrustes Analysis (GPA). Therefore, the aim was to determine the correlation between the effects of preslaughter feeding management and assessment by the panellists and review the sensory panel test results from a different viewpoint in more detail.

\section{Materials and Methods}

\section{Data Collection}

The data for the panel test used in this study was obtained from the study by Karaca et al. (2016). Eighty Norduz lambs at the age of 7 months reared in Yüzüncü Y1l University Research and Application Farm Sheep Breeding Facility were used as the animal material in the study. The lambs were divided into two diet groups of 40 as barley-supplemented alfalfa hay (BAH: $1.250 \mathrm{~g}$ alfalfa hay $+500 \mathrm{~g}$ barley/lamb/day) and only alfalfa hay (AH: $1.750 \mathrm{~g}$ lamb/day) in the short-term finishing period of 21 days. At the end of this period, ram lambs were divided into four groups of 20 with equal head from $\mathrm{AH}$ and $\mathrm{BAH}$ and were fasted for $0(0 \mathrm{~h}), 12(12 \mathrm{~h}), 24(24 \mathrm{~h})$ and $48(48 \mathrm{~h})$ hours before slaughter. The meat samples were stored at $18^{\circ} \mathrm{C}$ for the sensory panel test $\left(6^{\text {th }}-12^{\text {th }} \mathrm{m}\right.$. longissimus thoracis (LT) taken from right half carcass) and thawed by being kept at $+4^{\circ} \mathrm{C}$ for 24 hours. Then meat samples in aluminium foil were cooked in an electric oven at $180^{\circ} \mathrm{C}$ until their internal temperature reached $80^{\circ} \mathrm{C}$. The internal temperatures were monitored by geometrically measuring the midpoint of the meat and using probes connected to a Testo brand 175 T3 model data logger. Each cooked sample was cut into approximately $1 \mathrm{~cm}^{3}$ piece and kept in aluminium foil at $60^{\circ} \mathrm{C}$ until they were served to the panellists. Semi-trained panellists comprising 26 individuals were asked to evaluate the samples in terms of tenderness, juiciness, flavor and overall liking, rated on a scale of 1 (extreme dislike) to 9 (extremely good) (Karaca et al., 2016). During the sensory panel, 8 different samples were used in the evaluations and water and unsalted cracker was served to the panellists between samples.

\section{Statistical Analysis Methods}

In GPA the matching procedure is based on minimizing the distances between different panellists and the same object. The differences in distances for individual matrices may be stated as mentioned below.

$$
\sum_{\mathrm{k}<1}^{\mathrm{K}}\left\|\tau\left(\mathrm{X}_{\mathrm{k}}\right)-\tau\left(\mathrm{X}_{1}\right)\right\|
$$

$\tau\left(X_{k}\right), \tau\left(X_{k}\right)$ represent a certain transformation of the matrices $(\tau)$ and $M$ is the total of the squares of the elements.

$$
\|\mathrm{M}\|=\operatorname{tr}(\mathrm{MM})=\sum_{\mathrm{i}, \mathrm{j}} \mathrm{m}_{\mathrm{ij}}^{2}
$$

The points produced by transformation $(\tau)$ do not preserve relative distances. Firstly the minimization procedure is performed with the following equations.

$$
\sum_{\mathrm{k}=1}^{\mathrm{K}}\left\|\tau\left(\mathrm{X}_{\mathrm{k}}\right)-\mathrm{Y}\right\|
$$

and

$$
\mathrm{Y}=\mathrm{K}^{-1} \sum_{\mathrm{k}=1}^{\mathrm{K}} \tau\left(\mathrm{X}_{\mathrm{k}}\right)
$$

$\mathrm{Y}$ is the mean of the transformed individual data matrices $\left(\tau\left(X_{k}\right)\right)$ and is stated as the consensus matrix. The transformations used in the Procrustes analysis are translation, rotation and scaling. These transformations are stated below.

$$
\tau\left(X_{k}\right)=\rho_{k} X_{k} H_{k}+T_{k}
$$

$\rho_{\mathrm{k}}$, is the isotropic scaling factor, $\mathrm{H}_{\mathrm{k}}$ is the rotation matrix and $T_{k}$ is translation. The minimizing criteria for GPA are the totals of all quadratic distances between the transformed individual matrices and is stated as follows;

$$
\sum_{\mathrm{k}<1}^{\mathrm{K}}\left\|\rho_{\mathrm{k}} \mathrm{X}_{\mathrm{k}} \mathrm{H}_{\mathrm{k}}-\rho_{1} \mathrm{X}_{1} \mathrm{H}_{1}\right\|=\mathrm{K} \sum_{\mathrm{k}=1}^{\mathrm{K}}\left\|\mathrm{Y}-\rho_{\mathrm{k}} \mathrm{X}_{\mathrm{k}} \mathrm{H}_{\mathrm{k}}\right\|
$$

(Dijksterhuis, 1996; Tomic, 2013).

To assess the contribution of the transformations to the reduction in total variance, approximate F-tests are used to create Procrustes Analysis of Variance (PANOVA) tables for each of the three transformations (Tomic, 2013).

\section{Data Analysis}

In this study, GPA analysis was used for evaluation of sensory panel test results. At the same time, GPA was used to minimize the difference between the panellists. In the first stage, data matrices formed from 4 sensory characteristics and 8 meat samples were obtained for the 26 panellists (configuration). With the aim of reaching a consensus between the panellists with GPA analysis, score values of these matrices were matched by using three different transformations (translation, isotropic scaling and rotation/reflection). XLSTAT package program was used for GPA analysis.

\section{Results and Discussion}

The Procrustes Analysis of Variance (PANOVA) is the first step in GPA analysis and the effect of each transformation is obtained in terms of reduction of total variability (Table 1).

According to the PANOVA table, rotation and translation transformations had the highest effect in reducing total variability between the panellists $(\mathrm{P}<0.001)$. The panellist main effects were removed with the translation procedure and the variation was decreased by pooling them. Thus, the distances between different score values that panellists gave to the same sensory characteristics were minimized with the rotation transformation (Dijksterhuis, 1996). The isotropic scaling transformation did not contribute to reduction of the variability $(\mathrm{P}>0.05)$. Rodriques and Teixeira (2014) aimed 
to assess the meat obtained from two different pork breeds with sensory analysis using the GPA method with a data matrix of 4 meat samples, 4 sensory parameters and 10 panellists. The panellists found significant differences between the meat samples from different breeds. The errors of meat samples obtained after translation transformations were similar and low, with differences determined between the panellists.

The residual variance information for each group after rotation and translation transformations is presented in Table 2. As seen in Table 2, the groups which had the lowest residual were groups with most consensus provided by the panellists in terms of sensory characteristics (tenderness, juiciness, flavour and overall liking). Accordingly, while BAH-24 h and $\mathrm{AH}-12 \mathrm{~h}$ groups had the lowest residual and the highest panellist consensus, the highest residual value was obtained from $\mathrm{AH}-48 \mathrm{~h}$. This indicates that there was no consensus among the panellists for this group (AH-48 h group). However, other groups had similar residuals.

Alcade et al. (2014) in a study researching the effect of breed on sensory characteristics determined that with GPA analysis and 12 panellists, the breed with highest consensus and lowest error was Churra Lebrijana. They also emphasized that the GPA method was the most effective method to differentiate breeds in terms of sensory characteristics. In a study by Kor and Keskin (2011), 12 panellists assessed 10 meat samples with different genotypes and genders, and the lowest error rate was obtained for Angora Late Castrated group with a consensus in terms of sensory characteristics.

The residuals for each configuration (panellist) after transformation, scaling factors and variance changes explained by the first two principal components of GPA are given in Table 3 . The residuals obtained from 26 panellists were very close. But panellist 8 (32.142), panellist 13 (32.318), panellist 16 (32.163) and panellist 20 (32.666) had higher residual values, respectively. These results indicate that these panellists had lower consensus when compared to the other panellists. The scaling factors for each panellist are given in the second column of Table 3 .
Accordingly, the panellists whose scaling factors were higher than $1(5,6,10,11,12,13,14,15,16,17,20,21$ and 24) used a wider part of the scale, while the panellists whose scale factors were lower than $1(1,2,3,4,7,8,9$, $18,19,22,23,25$ and 26) used a narrow part of this scale. According to Rodriques and Teixeira (2013), some bias may occur as panellists evaluate the scale. Depending on these biases panellists may use a narrower or wider portion of the scale; however they stated that the transformations in GPA analysis easily resolve this situation.

The eigenvalues, variance and cumulative explanation ratios for 4 factors obtained from GPA are given in Table 4. The eigenvalues show the explanatory power of the variance for the sensory characteristics of each factor. According to Table 4, the highest eigenvalue was for the first factor (0.925) and this was followed by the second factor (0.875). At the same time, $100 \%$ of the total variability was explained by four factors. The first two factors (i.e. F1 and F2) of the consensus configuration explained $66.74 \%$ of total variability between groups. The remaining $33.36 \%$ of total variability is explained by the third factor and fourth factor.

Figure 1 represents the correlation between sensory characteristics, groups and the first two factors (i.e., F1 and F2) after principal component analysis (PCA) of GPA. While the first dimension of Figure 1 explains $34.31 \%$ of consensus variance, the second dimension explains $32.43 \%$ of this variance (Figure 1). There are lower correlations between BAH-12 h, BAH-24 h, BAH-48 h, AH-48 $h$ groups and sensory characteristics when compared to the other groups. Thus, it suggests that a fasting period longer than $24 \mathrm{~h}$ and barley-supplemented diet groups were preferred less by panellists. Moreover, while $\mathrm{AH}-24 \mathrm{~h}$ and $\mathrm{AH}-\mathrm{O} \mathrm{h}$ groups were located in the negative part of $\mathrm{F} 1$ and $\mathrm{F} 2, \mathrm{AH}-12 \mathrm{~h}$ and $\mathrm{BAH}-0 \mathrm{~h}$ groups were located in the positive part of F1. In addition, the flavour was highly correlated with these two groups. AH$0 \mathrm{~h}$ group had a higher correlation with tenderness, juiciness and overall liking and $\mathrm{AH}-24 \mathrm{~h}$ had low correlation with these characteristics in the same region.

Table 1 Procrustes analysis of variance for groups of sensory panel test

\begin{tabular}{|c|c|c|c|c|c|}
\hline Source & $\mathrm{DF}^{1}$ & $\mathrm{SSR}^{2}$ & $\mathrm{MSR}^{3}$ & $\mathrm{~F}$ & $\operatorname{Pr}^{4}$ \\
\hline Residuals after scaling transformation & 525 & 767.192 & 1.461 & & \\
\hline Scaling transformation & 25 & 47.182 & 1.887 & 1.291 & 0.158 \\
\hline Residuals after rotation & 550 & 814.374 & 1.481 & & \\
\hline Rotation & 150 & 403.982 & 2.693 & 1.843 & $<0.0001$ \\
\hline Residuals after translation & 700 & 1218.356 & 1.741 & & \\
\hline Translation & 100 & 371.952 & 3.720 & 2.545 & $<0.0001$ \\
\hline Corrected total & 800 & 1590.308 & 1.988 & & \\
\hline
\end{tabular}

Table 2 Residual variance for each group

\begin{tabular}{l|c}
\hline \multicolumn{1}{c|}{ Group $^{1}$} & Residual \\
\hline BAH-0 h & 101.211 \\
BAH-12 h & 95.706 \\
BAH-24 h & 86.826 \\
BAH-48 h & 90.874 \\
AH-0 h & 101.763 \\
AH-12 h & 87.815 \\
AH-24 h & 92.547 \\
AH-48 h & 110.450 \\
\hline
\end{tabular}


Table 3 Residual variance, scaling factors, and the variation percentage explained by the first two principal components of generalized Procrustes analysis (GPA) for each panellist

\begin{tabular}{l|cccc}
\hline Panellists & Residuals & Scaling factors & $\mathrm{F}^{1}, \%$ & $\mathrm{~F}^{2}, \%$ \\
\hline 1 & 26.440 & 0.870 & 31.757 & 36.637 \\
2 & 26.259 & 0.673 & 15.458 & 6.483 \\
3 & 27.623 & 0.677 & 6.689 & 10.384 \\
4 & 30.757 & 0.790 & 4.189 & 59.033 \\
5 & 28.445 & 2.065 & 8.167 & 51.792 \\
6 & 29.236 & 1.274 & 10.440 & 31.412 \\
7 & 28.111 & 0.919 & 42.866 & 4.378 \\
8 & 32.142 & 0.782 & 38.977 & 35.928 \\
9 & 29.760 & 0.983 & 27.545 & 12.070 \\
10 & 29.498 & 1.494 & 88.082 & 71.822 \\
11 & 29.747 & 1.380 & 5.201 & 70.891 \\
12 & 28.906 & 1.385 & 4.069 & 8.829 \\
13 & 32.318 & 1.605 & 49.143 & 1.507 \\
14 & 29.648 & 1.258 & 30.721 & 25.944 \\
15 & 30.970 & 1.219 & 48.123 & 12.692 \\
16 & 32.163 & 2.141 & 40.385 & 34.610 \\
17 & 30.420 & 1.172 & 36.396 & 6.524 \\
18 & 25.674 & 0.668 & 72.920 & 71.485 \\
19 & 28.930 & 0.779 & 4.941 & 44.613 \\
20 & 32.666 & 1.326 & 46.072 & 38.088 \\
21 & 29.059 & 1.199 & 36.805 & 11.066 \\
22 & 26.490 & 0.914 & 46.368 & 57.318 \\
23 & 31.228 & 0.738 & 38.561 & 58.816 \\
24 & 30.723 & 1.312 & 16.117 & 9.866 \\
25 & 28.308 & 0.715 & 66.295 & 17.159 \\
26 & 31.671 & 0.966 & 57.025 & \\
\hline
\end{tabular}

${ }^{1}$ F1: First principal component of GPA; ${ }^{2}$ F2: Second principal component of GPA

Table 4 The eigenvalues, variability and cumulative variability

\begin{tabular}{c|ccc}
\hline Factors & Eigenvalue & Variability, \% & Cumulative, $\%$ \\
\hline Factor 1 (F1) & 0.925 & 34.308 & 34.308 \\
Factor 2 (F2) & 0.875 & 32.430 & 66.738 \\
Factor 3 (F3) & 0.574 & 21.261 & 88.000 \\
Factor 4 (F4) & 0.324 & 12.000 & 100.000 \\
\hline
\end{tabular}

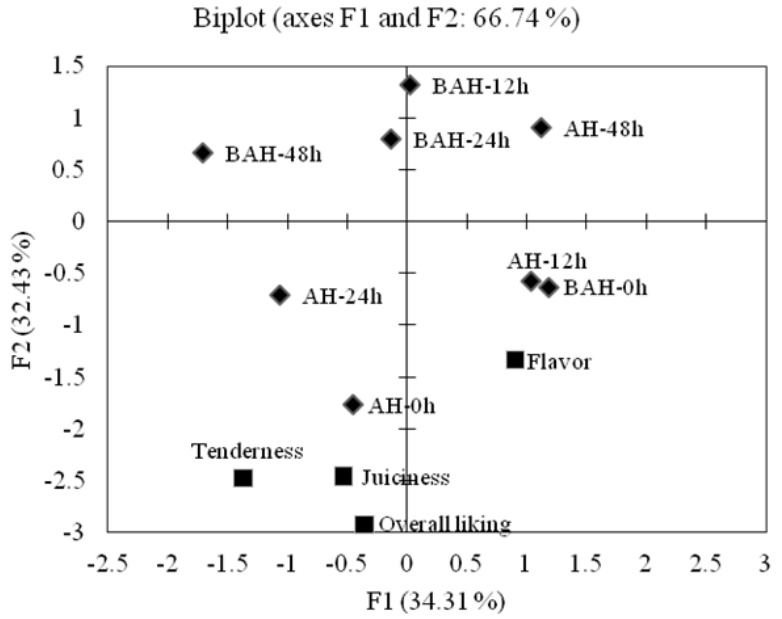

As a result, 26 panellists evaluated the $\mathrm{AH}-12 \mathrm{~h}$ and $\mathrm{BAH}-0 \mathrm{~h}$ groups as being tastier and they much preferred the $\mathrm{AH}-0 \mathrm{~h}$ group in terms of tenderness, juiciness and overall liking. Rodriques and Teixeira (2013) used the GPA method to evaluate the sensory characteristics of Terrincho lamb meat. Research into the effect of gender and carcass weight on sensory properties (toughness, juiciness, flavour intensity, odour intensity, stringiness, and level of sweetness) found that the two factors explained $72.76 \%$ of the total variation. Additionally, the 11 panellists on the panel could not distinguish any gender effect; however, they found the meat of heavier animals was harder and had more intensive odour while the meat of lighter animals was more succulent. Keskin et al. (2012) obtained 6 meat samples from different species (sheep and goats) and feeding (pasture and fattening) systems and completed GPA analysis with 10 panellists and 5 sensory characteristics (colour, texture, odour, taste and acceptability). They found $61.11 \%$ of the total variation was explained by the two factors. Additionally, the panellists chose the meat of sheep and goats raised under pasture conditions in terms of sensory characteristics over that of animals raised under fattening conditions.

\section{Conclusion}

The evaluation of the sensory panel test using GPA analysis assesses attitudes and behaviour of panellists in a sensory test and reviews the detailed effects of diet and fasting period on sensory characteristics. Longer fasting 
periods have a negative effect on consensus among panellists. It was determined that barley-supplemented groups were preferred less by panellists. Most of the panellists have a reconciliatory tendency among themselves while evaluating the groups. In conclusion, it is possible to say that GPA analysis is an important method to assess attitudes/behaviour of panellists in a sensory test.

\section{Acknowledgement}

I would like to thank project leader Serhat Karaca and project team for providing sensory data. Additionally, an abstract of this paper was published as a book of abstracts in $1^{\text {st }}$ International GAP Agriculture and Livestock Congress (UGAP 2018), April 25-27, 2018 (pp:140) in SANLIURFA- Turkey.

\section{References}

Adnøy T, Haug A, Sørheim O, Thomassen MS, Varszegi Z, Eik LO. 2005. Grazing on mountain pastures - does it affect meat quality in lambs?. Livestock Production Science, 94: 25-31.

Alcalde MJ, Moreno-Indias I, Horcado A, Molina A, Juarez M. 2014. Generalized procrustes analysis (GPA) as a tool to discriminate sheep breeds. Archiv. Tierzucht, 57: 1-10.

Dijksterhuis G. 1996. Procrustes analysis in sensory research. http://www.econ.upf.edu/docs/seminars/dijksterhuis3.pdf [Erişim: 19.08.2016].

Ekiz B, Yılmaz A, Özcan M, Kaptan C, Hanoğlu H, Erdoğan I, Yalçıntan H. 2009. Carcass measurements and meat quality of Turkish Merino, Ramlic, Kivircik, Chios and Imroz lambs raised under an intensive production system. Meat Science, 82: 64-70.

Ferguson DM, Warner RD. 2008. Have we underestimated the impact of pre-slaughter stress on meat quality in ruminants. Meat Science, 80: 12-19.

Font-i-Furnols M, Guerrero L. 2014. Consumer preference, behavior and perception about meat and meat products: an overview. Meat Science, 98: 361-371.
Guerrero A, Velandia Valero M, Campo MM, Sañudo C. 2013. Some factors that affect ruminant meat quality: from the farm to the fork. Review Acta Scientiarum Animal Sciences, 35: 335-347.

Honikel KO. 2004. Conversion of Muscle to Meat. (Editors: Jensen, Devine, Dikeman) Encyclopedia of Meat Sciences. Academic Press, London. Pp: 238-242.

Karaca S, Erdoğan S, Kor D, Kor A. 2016. Effects of preslaughter diet/management system and fasting period on physiological indicators and meat quality traits of lambs. Meat Science, 116: 67-77.

Keskin S, Kor A, Karaca S. 2012. Evaluation of sensory characteristics of sheep and goat meat by Procrustes Analysis. Czech Journal of Animal Science, 57: 516-521.

Kor A, Keskin S. 2011. Quality and sensory evaluation for goat meat using generalized procrustes analysis. Journal of Animal and Veterinary Advances, 10: 1313-1316.

Rodriques S, Teixeira A. 2009. Effect of sex and carcass weight on sensory quality of goat meat of Cabrito Transmontano. Journal of Animal Science, 87: 711-715.

Rodriques S, Teixeira A. 2013. Use of generalized procrustes analysis (GPA) to test the effects of sex and carcass weight on sensory quality evaluations of Terrincho lamb meat. Meat Science, 93: 485-488.

Rodriques S, Teixeira A. 2014. Effect of breed and sex on pork meat sensory evaluation. Food and Nutrition Sciences, 5: 599-605.

Sanudo C, Campo M, Olleta JL, Joy M, Delfa R. 2007. Evaluation of carcass and meat quality in cattle and sheep. Methodologies to Evaluate Meat Quality in Small Ruminants (EAAP No 123: 225), Wageningen Academic Publishers, Netherlands.

Tomic O. 2013. Differences between generalised procrustes analysis and multiple factor analysis in case of projective mapping. Master dissertation. Norwegian University of Life Sciences, Norwegian.

Wu W, Roberts SLL, Armitage JR, Tooke P, H. Cordingley HC, Wildsmith SE. 2003. Validation of consensus between proteomic and clinical chemistry datasets by applying a new randomisation $F$-test for generalised procrustes analysis, Analytica Chimica Acta, 490: 365-378. 